\title{
Endothelium-Derived Relaxing Factor: Presence in Pulmonary and Systemic Arteries of the Newborn Guinea Pig
}

\author{
DENNIS DAVIDSON AND ALAA ELDEMERDASH \\ Division of Neonatal-Perinatal Medicine, Schneider Children's Hospital of Long Island Jewish Medical Center, \\ The Long Island Campus for the Albert Einstein College of Medicine, New Hyde Park, New York 11042
}

\begin{abstract}
Endothelium-derived relaxing factor (EDRF), believed to be nitric oxide or a compound that releases nitric oxide, is a potent vasodilator produced by some arteries in response to acetylcholine $(\mathrm{ACh})$ and bradykinin (BK). ACh and BK are potent dilators of perinatal pulmonary and systemic arteries. The objectives of this study were to determine if EDRF is present in newborn vessels and if EDRF mediates the vasodilator actions of ACh and BK. Arterial rings from newborn guinea pigs, 1 to $3 \mathrm{~d}$ old, were obtained from a branch of the main pulmonary artery and the descending aorta for isometric force bioassays. At their optimal resting tension, the rings were preconstricted with phenylephrine $10^{-5} \mathrm{M}$ in KrebsHenseleit solution before adding incremental doses of $\mathrm{ACh}$ or BK. If the endothelium was intact, $\mathrm{ACh}\left(10^{-5} \mathrm{M}\right)$ relaxed pulmonary arteries and aortas $(64 \pm 7 \%, 72 \pm 9 \%$ relaxation, respectively, mean $\pm \mathrm{SE}$ ). $\mathrm{ACh}$-induced relaxation $\left(\mathrm{ACh} 10^{-5} \mathrm{M}\right)$ in the pulmonary artery and aorta, respectively, was significantly $(p<0.05)$ attenuated by 1$)$ endothelial removal $(11 \pm 9 \%, 28 \pm 10 \%)$ by rubbing the ring lumen; 2) methylene blue, $10^{-6} \mathrm{M},(6 \pm 8 \%, 7 \pm 3 \%)$ that inhibits EDRF-associated cGMP production in smooth muscle; and 3) methemoglobin, $10^{-5} \mathrm{M},(13 \pm 9 \%, 17 \pm$ $7 \%$ ) that binds EDRF. The results for BK were similar to $\mathrm{ACh}$ for the pulmonary artery but BK did not relax the aorta. Indomethacin diminished relaxation of the pulmonary artery and aorta to the submaximal dose $\left(10^{-5} \mathrm{M}\right)$ of $\mathrm{ACh}$ but indomethacin did not effect the relaxation to $\mathrm{ACh}$ $10^{-4} \mathrm{M}$ or BK. We conclude that EDRF is produced in the guinea pig pulmonary artery and descending aorta at birth and that EDRF is a mediator of the vasodilator actions of $\mathrm{ACh}$ and BK. Vasodilation by ACh may also involve activation of the cyclooxygenase pathway. (Pediatr Res 27: 128-132, 1990)
\end{abstract}

\section{Abbreviations}

EDRF, endothelium-derived relaxing factor ACh, acetylcholine

BK, bradykinin

EDRF, now believed to be nitric oxide or a compound that releases nitric oxide, was discovered in 1980 when acetycholine

Received June 16, 1989; accepted September 22,1989.

Correspondence Dennis Davidson, M.D., Division of Neonatal-Perinatal Medicine, Schneider Children's Hospital of Long Island Jewish Medical Center, New Hyde Park, NY 11042.

Supported by an Edward Livingston Trudeau Scholar Award (D.D.) from the American Lung Association. was found to relax preconstricted rabbit artery strips in vitro only if the luminal endothelial cell lining was intact (1). Subsequently, EDRF has been identified by bioassay techniques in pulmonary and systemic arteries of many mammalian species and substances other than ACh (e.g. BK and calcium ionophore) have been shown to stimulate EDRF production. Based on a rapidly expanding body of work (2) that followed the discovery of EDRF, certain bioassay criteria have evolved for attributing vasodilatation to EDRF. These include inhibition of vascular relaxation: 1) after removal of or injury to luminal endothelium of the blood vessel $(1) ; 2$ ) by pretreatment with methylene blue that inhibits the increase in cGMP in smooth muscle cells associated with EDRF production (3); and 3) by pretreatment with methemoglobin or $\mathrm{Hb}$ that binds EDRF (4).

EDRF has not previously been described in pulmonary and systemic blood vessels at birth. It is known that $\mathrm{ACh}(5)$ and $\mathrm{BK}$ are potent dilators of the perinatal pulmonary circulation and BK has been implicated as a mediator of the circulatory adjustments at birth (6). Therefore, our experiments were designed to determine if EDRF is present immediately after birth in the guinea pig pulmonary artery and abdominal aorta and to determine if EDRF mediates the vasodilator actions of $\mathrm{BK}$ and $\mathrm{ACh}$ in blood vessels at birth. A better understanding of the biochemical control of the perinatal pulmonary circulation is needed because an attenuation of the decrease in pulmonary vascular resistance at birth can lead to severe respiratory distress and persistent pulmonary hypertension of the newborn.

\section{MATERIALS AND METHODS}

Arterial ring bioassay. Newborn Duncan-Hartley guinea pigs, $1-3 \mathrm{~d}$ old $(1.3 \pm 0.3 \mathrm{~d}$, mean $\pm \mathrm{SE})$ were weighed $(89 \pm 3 \mathrm{~g})$ and anesthetized with pentobarbital $100 \mathrm{mg} / \mathrm{kg}$ intraperitoneally. After a midline abdominal and thoracic incision, heparin (100 $U$ ) was injected into the right ventricle. The heart and lungs were rapidly removed together and placed in ice cold Krebs-Henseleit solution. The abdominal aorta distal to the renal arteries was then carefully dissected away from connecting tissues and placed in standard Krebs-Henseleit solution. One vascular ring, 3-4 $\mathrm{mm}$ in length, was taken from the abdominal aorta and the first branch of the pulmonary artery (distal to the ductus arteriosus). Care was taken, during dissection and hook insertion, to avoid injury to the endothelial lining. In a separate set of studies, the endothelium was intentionally rubbed off the lumen of some rings by pulling the ring by its adventitia along a stainless steel wire inserted through the ring lumen.

Each ring was mounted in a $10-\mathrm{mL}$, water-jacketed, organ chamber by stainless steel hooks inserted gently into the ring lumen. The Krebs-Henseleit bath $\left(38^{\circ} \mathrm{C}\right)$ was bubbled with a gas mixture to maintain a $\mathrm{pH}$ of $7.42 \pm 0.02, \mathrm{PCO}_{2}$ of $30 \pm 1$ torr, 
and $\mathrm{PO}_{2}$ of $574 \pm 10$ torr (1). Blood vessel tension was recorded from a Grass FTO3C isometric force transducer and model 7 polygraph (Grass Instrument Co., Quincy, MA).

The rings were gradually stretched $(3-4 \mathrm{~h})$ using a micrometer to give an initial resting tension of $1 \mathrm{~g}$. The selected resting force for optimal contraction was then chosen based on serial depolarizations using a modified Krebs-Henseleit solution in which $\mathrm{NaCl}$ was replaced by $\mathrm{KCl}$, yielding a $9.4 \mathrm{mM} \mathrm{KC1}$ solution. Between drug administrations, the bioassay chamber was washed with standard Krebs-Henseleit without changing bath temperature and a steady baseline tension was recorded for $15 \mathrm{~min}$. The rings were then exposed to cumulative doses of phenylephrine from $10^{-8}$ to $10^{-4} \mathrm{M}$ in increments of 10 -fold concentration. Based on preliminary experiments, we found that phenylephrine $10^{-5} \mathrm{M}$ produced a near maximal response $\left(\mathrm{ED}_{50}=3 \times 10^{-7} \mathrm{M}\right)$. Therefore, all rings tested for relaxation were evaluated during a contraction to phenylephrine $10^{-5} \mathrm{M}$. Any ring that could not increase tension by $0.25 \mathrm{~g}$ in response to phenylephrine $10^{-5} \mathrm{M}$ was not studied.

Some rings with endothelium removed were treated with phenylephrine followed by incremental doses of papaverine, a direct smooth muscle relaxing agent, to determine if smooth muscle relaxation could still occur after rubbing. At the end of the experiment some rings (rubbed and unrubbed) were examined by light microscopy to assess the condition of the luminal surface. After cutting the rings longitudinally, the luminal surface was stained with $2 \% \mathrm{AgNO}_{3}$ for $5 \mathrm{~min} . \mathrm{AgNO}_{3}$ preferentially stains the endothelial cell membrane (1). Preliminary studies indicated that excessive rubbing to remove all endothelial cells from these neonatal arteries was one cause for a poor contractile response to phenylephrine. Therefore, limited rubbing that removed almost all the endothelial cells, was required.

Determination of EDRF production. After a steady increase in tension was achieved with phenylephrine, ring relaxation in response to both $\mathrm{ACh}$ or $\mathrm{BK}$ was studied at the following concentrations: $10^{-8}, 10^{-7}, 10^{-6}$, and $10^{-5} \mathrm{M}$, in rings with intact and rubbed lumens. For rings with intact endothelial cells, $\mathrm{ACh}$ and BK experiments were repeated with methemoglobin $10^{-5} \mathrm{M}$ added after phenylephrine constriction but before $\mathrm{ACh}$ or $\mathrm{BK}$ administration. Methemoglobin binds EDRF thereby inhibiting vascular relaxation (7). Some rings exposed to $\mathrm{BK}$ in the presence of methemoglobin were also exposed to papaverine, $10^{-8}$ to $10^{-5}$ $\mathrm{M}$, to determine if smooth muscle relaxation could still occur. Methylene blue, $10^{-6} \mathrm{M}$, was administered to baths with rings having intact endothelium, after preconstriction and before attempting relaxation with $\mathrm{ACh}$. Methylene blue inhibits EDRF vasodilatation and production of cGMP in smooth muscle (3, 4). Inasmuch as baseline tension was variable after methylene blue was washed from the bath, methylene blue was only used at the end of the experimental protocol and for ACh studies only.

During a contraction to phenylephrine, pulmonary arterial and descending aortic rings with intact endothelium were used to study relaxation to cumulative incremental doses of $\mathrm{ACh}, \mathrm{BK}$, or arachidonic acid before and after an 0.5 -h exposure to indomethacin $20 \mu \mathrm{M}$ to block the cyclooxygenase pathway (3).

Materials. Phenylephrine hydrochloride, ACh chloride, BK, methemoglobin, methylene blue, papaverine, indomethacin-sodium, and arachidonic acid-sodium were obtained from Sigma Chemical Company (St. Louis, MO). All drugs were dissolved in deionized water. Indomethacin was made up fresh as a $10-\mathrm{mM}$ solution with $100 \mathrm{mM} \mathrm{NaHCO}$. Standard Krebs-Henseleit solution contains $\mathrm{NaCl} 118 \mathrm{mM}, \mathrm{NaHCO}_{3} 25 \mathrm{mM}, \mathrm{KCl} 4.7 \mathrm{mM}$, $\mathrm{CaCl}_{2} 2.5 \mathrm{mM}, \mathrm{MgCl} 1.2 \mathrm{mM}, \mathrm{NaH}_{2} \mathrm{PO}_{4} 1.1 \mathrm{mM}$, and dextrose $11.1 \mathrm{mM}$.

Statistical analysis. Results are expressed as mean \pm SE. The principal endpoints analyzed statistically were the relaxation responses to $10^{-5} \mathrm{M}$ concentrations of $\mathrm{ACh}$ and $\mathrm{BK}$. Comparisons were made by analysis of variance followed by unpaired $t$ testing corrected by the Bonferonni method for multiple comparisons (8).

\section{RESULTS}

Baseline isometric tension was not different in intact compared to endothelium-removed pulmonary artery rings $(1.1 \pm 0.1 \mathrm{~g})$ and intact compared to endothelium-removed descending aortic rings $(1.3 \pm 0.1 \mathrm{~g})$. There was no difference between rings with intact endothelium or endothelium-removed regarding the percent increase in baseline tension after phenylephrine administration. Phenylephrine $\left(10^{-5} \mathrm{M}\right)$ raised pulmonary arterial ring tension by $48 \pm 7 \%$ (to $1.63 \pm 0.11 \mathrm{~g}$ ) and abdominal aortic ring tension by $42 \pm 8 \%$ (to $1.85 \pm 0.15 \mathrm{~g}$ ). Light microscopy of $\mathrm{AgNO}_{3}$-stained rings confirmed an intact endothelial lining (unrubbed vessels) and nearly complete removal of endothelium (rubbed vessels) as shown in Figure 1.

Effect of ACh on preconstricted pulmonary artery and aortic rings. Figure 2 shows typical polygraph tracings depicting the effect of endothelial cell removal on ACh-induced relaxation in pulmonary arterial rings. ACh produced a concentration-dependent relaxation of both preconstricted pulmonary artery and descending aorta (Fig. 3). Relaxation is defined as the percent decrease in tension caused by $\mathrm{ACh}$ or $\mathrm{BK}$ during a contraction to phenylephrine $\left(10^{-5} \mathrm{M}\right)$. For example, if phenylephrine $\left(10^{-5}\right.$
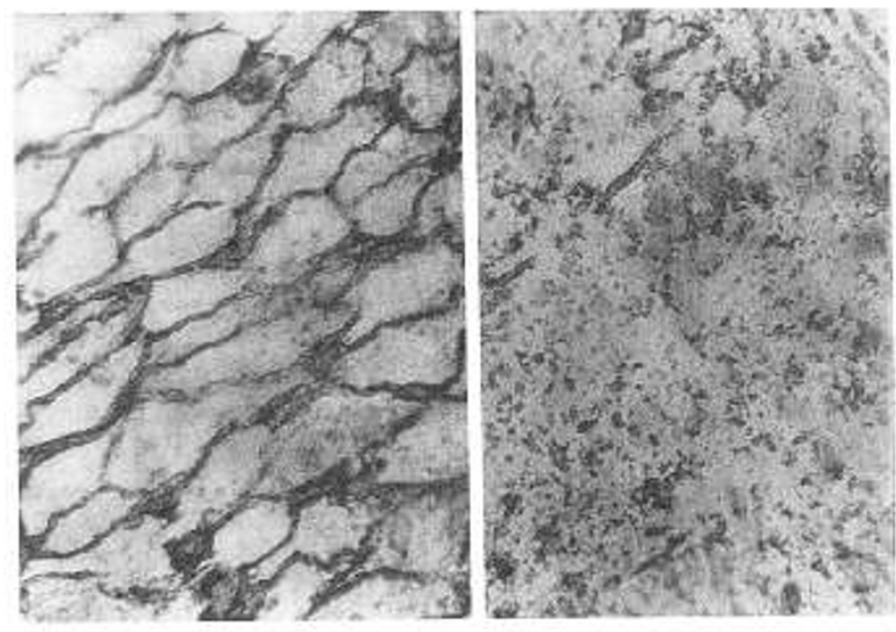

Fig. 1. Light microscopic views ( $x 400$, silver nitrate stain) of the luminal surface of a pulmonary artery from the newborn guinea pig. The panel on the left shows an intact endothelial surface, whereas the panel to the right shows the surface after removal of endothelial cells by rubbing.

\section{ENDOTHELIUM PRESENT}
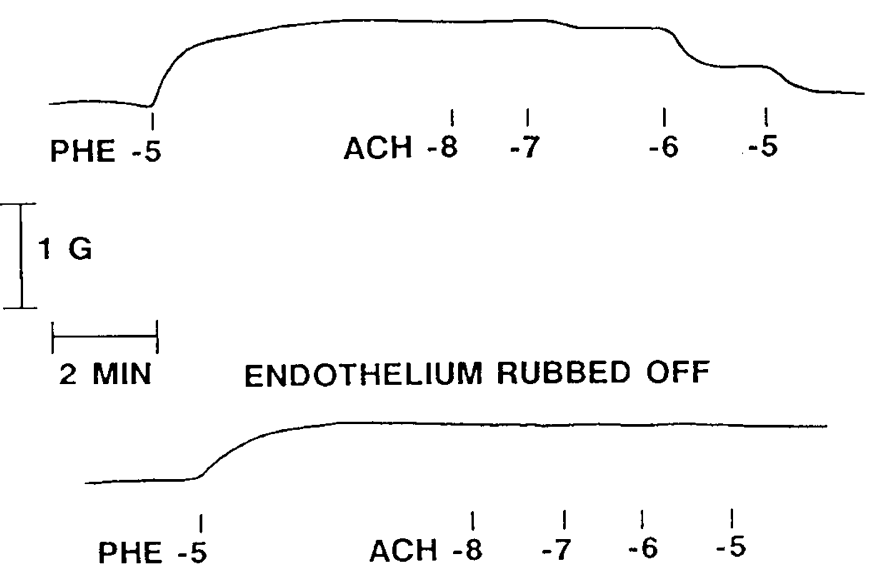

Fig. 2. Polygraph tracings demonstrating relaxation of a 1-d-old guinea pig pulmonary artery ring in vitro by ACh during a contraction by phenylephrine. Removal of the endothelial cell lining inhibited AChinduced relaxation. 


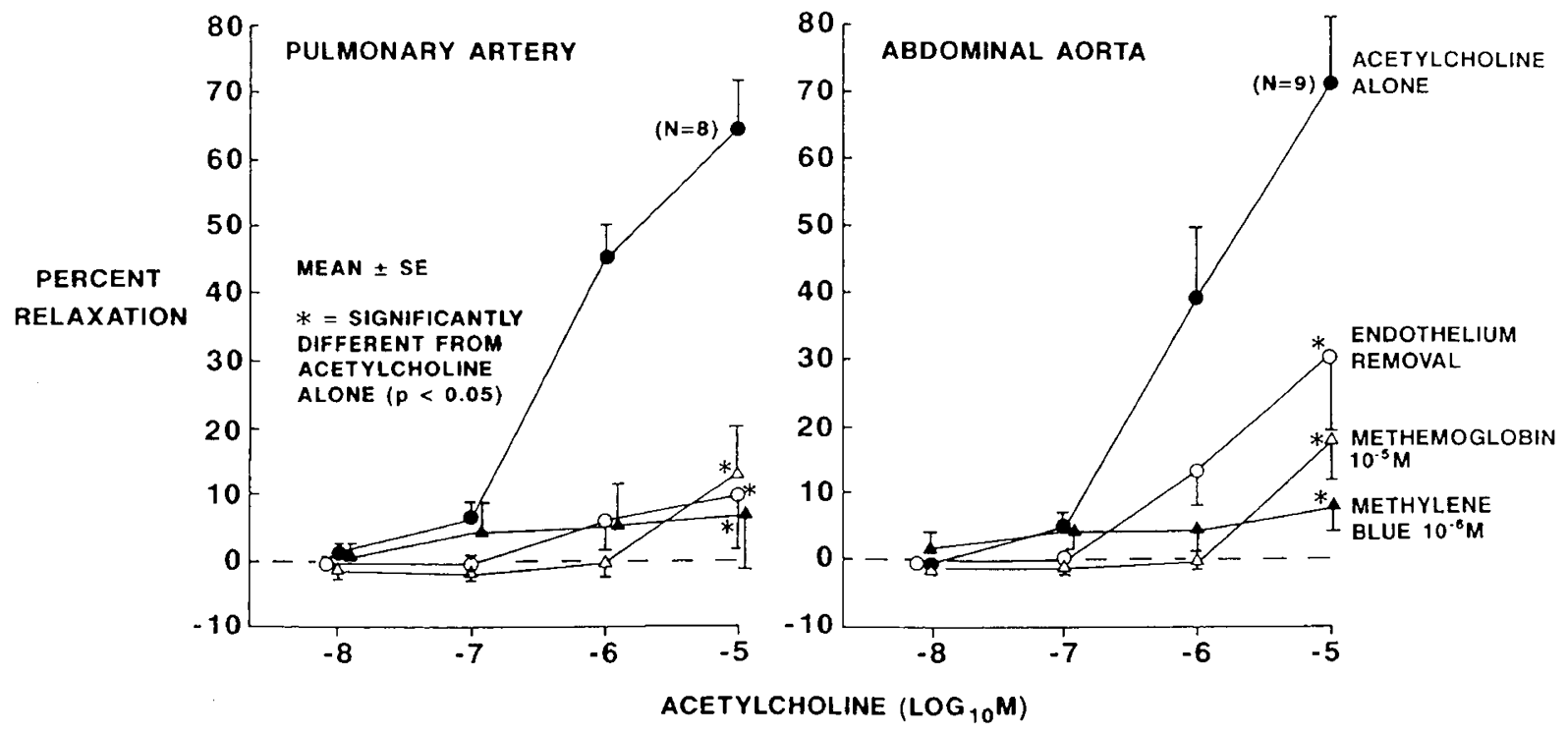

Fig. 3. ACh-induced relaxation of newborn guinea pig pulmonary arterial (left panel) and descending aortic (right panel) rings in vitro during a contraction by phenylephrine. Removal of the endothelial cell lining,methylene blue, and methemoglobin markedly attenuated ACh-induced relaxation.

$\mathrm{M}$ ) increased ring tension by $1 \mathrm{~g}$ above baseline and $\mathrm{ACh}$ (with or without an EDRF inhibitor) reduced tension to $0.75 \mathrm{~g}$ above baseline, then a $25 \%$ relaxation has occurred. If an agent such as $\mathrm{BK}$ increases ring tension from 1 to $1.25 \mathrm{~g}$ then this is referred to as a $-25 \%$ change in tension. ACh $\left(10^{-5} \mathrm{M}\right)$ relaxed preconstricted pulmonary artery and aorta by $64 \pm 7 \%(n=8)$ and 72 $\pm 9 \%(n=9)$, respectively.

Relaxation by $\mathrm{ACh}\left(10^{-5} \mathrm{M}\right)$ was attenuated by: 1$)$ endothelium removal (relaxation, $11 \pm 9 \%$ pulmonary artery, $28 \pm 10 \%$ aorta); 2) methemoglobin, $10^{-5} \mathrm{M}(13 \pm 9 \%$ pulmonary artery, $17 \pm 7 \%$ aorta), and 3) methylene blue, $10^{-6} \mathrm{M}(6 \pm 8 \%$ pulmonary artery, $7 \pm 3 \%$ aorta). When pulmonary arterial and aortic rings that had their endothelium removed were preconstricted with phenylephrine, papaverine $\left(10^{-5} \mathrm{M}\right)$, a direct smooth muscle relaxing agent, totally relaxed the rings to baseline tension.

Effect of BK on preconstricted pulmonary artery and aortic rings. $\mathrm{BK}$ produced a dose-related relaxation of the preconstricted pulmonary arterial ring with intact endothelium (Fig. 4). Relaxation of the pulmonary arterial ring by BK $10^{-5} \mathrm{M}$ was 53 $\pm 6 \%(n=6)$ and was attenuated by 1$)$ endothelium removal $(13 \pm 13 \%)$ and 2$)$ methemoglobin, $10^{-5} \mathrm{M}(13 \pm 12 \%)$. BK did not relax the aorta $(n=7)$, the response was highly variable and the average response was one of increased tone (depicted by a negative percent change from base line in Fig. 4). The aortic response to $\mathrm{BK}$ was not different whether the endothelium was intact or removed, or whether the intact ring was exposed to methemoglobin.

Papaverine $\left(10^{-5} \mathrm{M}\right)$ could cause nearly total relaxation $(96 \pm$ $1 \%)$ of preconstricted aortic rings after the $\mathrm{BK}$ experiments. Papaverine $\left(10^{-5} \mathrm{M}\right)$ led to total relaxation of two pulmonary arterial rings with intact endothelium that did not relax with BK $\left(10^{-5} \mathrm{M}\right)$ in the presence of methemoglobin $\left(10^{-5} \mathrm{M}\right)$.

Effect of indomethacin on arterial relaxation by arachidonic acid, $B K$, and $A C h$. Using rings contracted with phenylephrine, we examined the effect of indomethacin $(20 \mu \mathrm{M}$, cyclooxygenase inhibitor) on pulmonary arterial $(n=8)$ and aortic $(n=7)$ ring tension during administration of arachidonic acid, $\mathrm{ACh}$, or $\mathrm{BK}$. Exogenous arachidonic acid $\left(10^{-4} \mathrm{M}\right)$ relaxed the pulmonary artery by $13 \pm 2 \%$ but increased tension in the aorta by $47 \pm$ 7\%. After indomethacin, arachidonic acid caused no relaxation in the pulmonary artery and changed the aortic response to $-9 \pm$ $9 \%$, suggesting an appreciable inhibition of cyclooxygenase activity was present.
Indomethacin attenuated relaxation in the pulmonary artery and aorta as shown in Figure 5. For both vessels, the ACh concentration versus relaxation curve was shifted to the right and relaxation in response to $\mathrm{ACh} 10^{-5}$ was significantly reduced by indomethacin. Indomethacin had no significant effect on BKinduced relaxation in the pulmonary artery and no effect on the BK-induced variable change in tension of the aorta. BK-induced $\left(10^{-5} \mathrm{M}\right)$ relaxation of the pulmonary artery was $45 \pm 6$ and 38 $\pm 8 \%$ for the control and indomethacin groups, respectively. BK-induced $\left(10^{-5} \mathrm{M}\right)$ changes from baseline tension for the aorta were $-85 \pm 53 \%$ (control) and $-32 \pm 17 \%$ (indomethacin).

\section{DISCUSSION}

Our study demonstrates that EDRF can be produced in the guinea pig pulmonary artery and descending aorta at birth. AChinduced relaxation of preconstricted pulmonary arterial and descending aortic rings in vitro could be attributed largely to EDRF because its action was markedly attenuated by endothelial cell removal (1), methemoglobin (7), and methylene blue $(3,4)$. BK-induced relaxation of the pulmonary artery could also be attributed principally to EDRF, but BK had no consistent effect on aortic tone. To our knowledge, EDRF production has not been previously demonstrated in pulmonary and systemic blood vessels immediately after birth. An EDRF is produced in human umbilical vascular endothelial cells stimulated by histamine but not ACh (9).

After demonstrating ACh- and BK-induced relaxations of the newborn guinea pig blood vessels, we tested several methods known to inhibit EDRF production or action on vascular relaxation. First, the method of endothelial cell rubbing was effective in markedly diminishing relaxation but not impairing vasoconstrictive responses to phenylephrine and vasodilating responses to papaverine in comparison to the pulmonary arterial or aortic ring with intact endothelium. The effectiveness of rubbing the ring lumen on endothelial cell removal was confirmed by light microscopy. We found nearly complete endothelial cell removal; this may explain why we markedly attenuated but did not abolish relaxation in response to ACh and BK. Second, methemoglobin or $\mathrm{Hb}$ inhibition of EDRF is often used as a criteria that one must meet to demonstrate EDRF production by bioassay $(2,7)$. Methemoglobin and $\mathrm{Hb}$, the latter used more commonly because it is more potent, appears to bind EDRF as it is produced by the endothelial cell. In our study we found that when pulmonary 


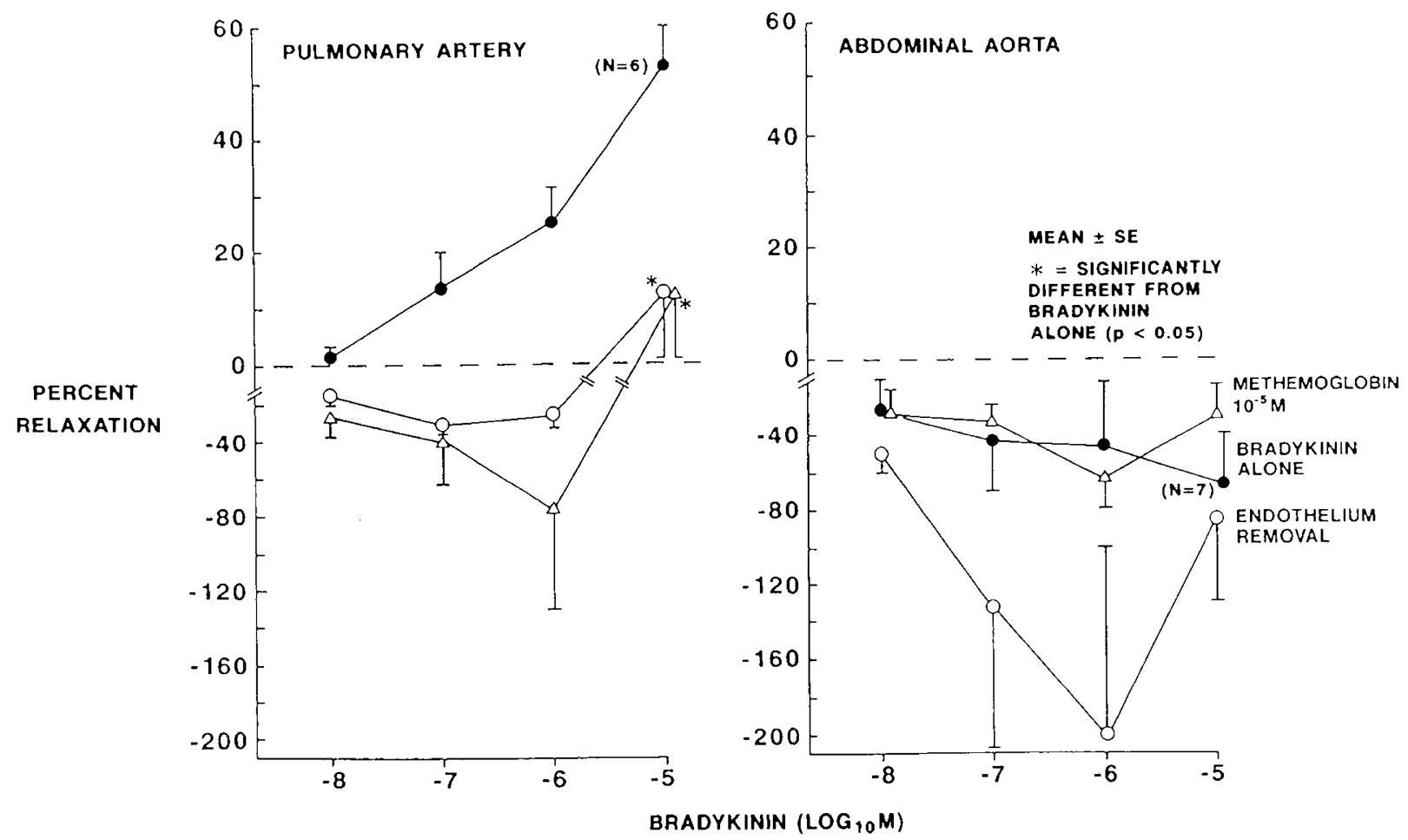

Fig. 4. BK-induced changes in vascular tone of newborn guinea pig pulmonary arterial (left panel) and descending aortic (right panel) rings in vitro during a contraction by phenylephrine. Removal of the endothelial cell lining and methemoglobin markedly attenuated BK-induced relaxation of the pulmonary artery. BK did not relax aortic rings.

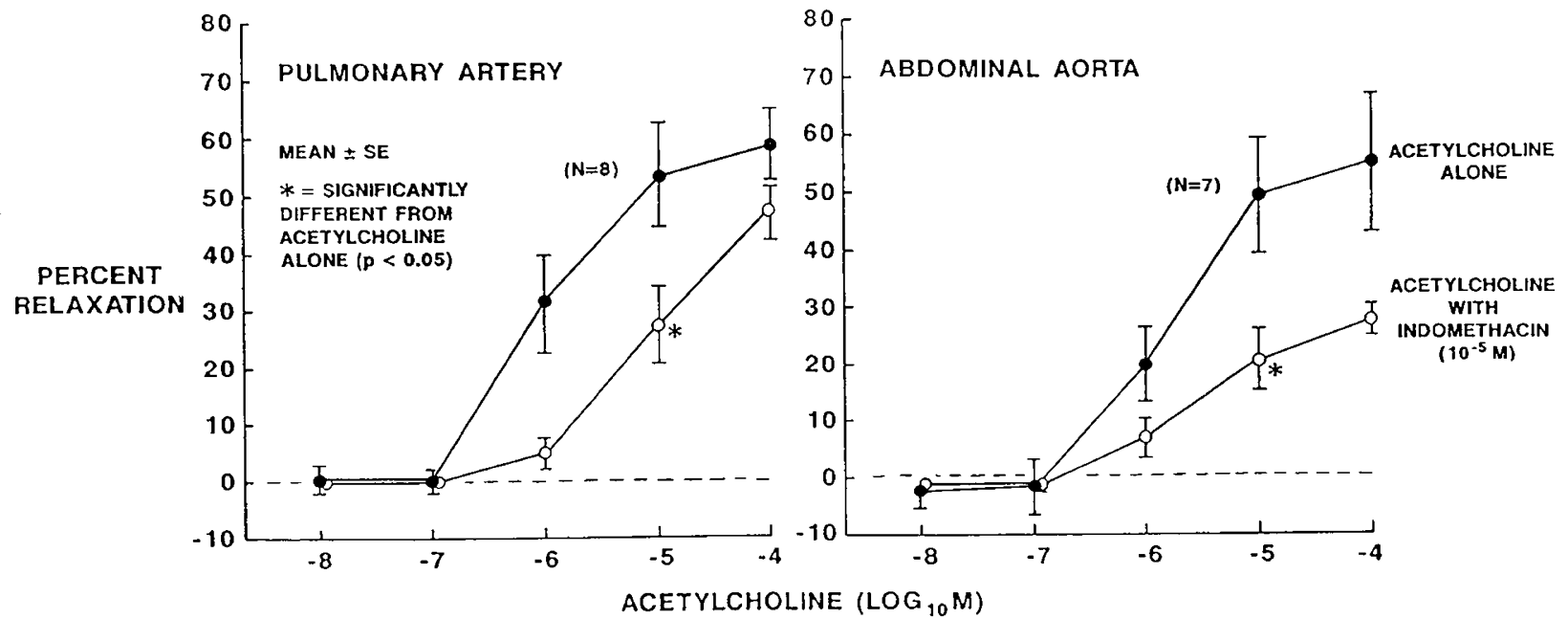

Fig. 5. ACh-induced relaxation of newborn guinea pig pulmonary arterial (left panel) and descending aortic (right panel) rings in vitro during a contraction by phenylephrine. Indomethacin attenuated acetycholine-induced relaxation in both arteries.

vascular relaxation by $\mathrm{BK}$ was inhibited by methemoglobin, we could still achieve relaxation if papaverine (a direct smooth muscle relaxing agent) was then added to the bath. This indicates that methemoglobin was not having a direct inhibitory effect on smooth muscle relaxation and supports the proposal that methemoglobin combines with EDRF resulting in an inhibition of EDRF-induced relaxation (2). Third, methylene blue inhibited acetylcholine-induced relaxation in our study (2-4). Methylene blue inhibits the action of EDRF by inhibiting the associated increase in guanylate cyclase activity and thus CGMP production in smooth muscle.

The original report describing EDRF (1) and the extensive literature that has accumulated since (2), does not support the possibility that EDRF is a product of the cyclooxygenase pathway because indomethacin does not inhibit production of EDRF
(10). The identity of EDRF is now considered to be nitric oxide or a precursor compound that releases nitric oxide $(2,11)$. We did not expect to see an effect of indomethacin on ACh-induced relaxation because we had previously shown that this relaxation was almost completely inhibited by methylene blue and methemoglobin. These EDRF inhibitors do not theoretically block the production or action of a cyclooxygenase metabolite such as the vasodilator prostacyclin. Inasmuch as BK has been shown to stimulate prostacyclin production from endothelial cells (12), we expected that indomethacin might attenuate BK more than AChinduced relaxation. In our study indomethacin did not attenuate the BK-induced relaxation of the pulmonary artery and this was compatible with the results that BK-induced relaxation was markedly inhibited by methemoglobin suggesting a principal role for EDRF. Our results with ACh could be explained by a 
nonspecific action of indomethacin on $\mathrm{ACh}$-induced EDRF production, e.g. lipoxygenase inhibitors can inhibit EDRF (13), or that products of the cyclooxygenase pathway may be coupled with EDRF production as demonstrated in coronary arteries of the adult pig (14) using indomethacin at $10^{-5} \mathrm{M}$. Despite our unexpected results with $\mathrm{ACh}$, the fact that indomethacin had no effect on relaxation caused by the highest concentration of $\mathrm{ACh}$ $\left(10^{-4} \mathrm{M}\right)$ and $\mathrm{BK}$, supports our conclusion that EDRF is present in guinea pig blood vessels at birth.

Whether EDRF plays an important role in the circulatory adjustments at birth will be an interesting area for future research. Vasodilator substances such as BK (6) and prostacyclin (15) have been implicated as mediators of the decrease in pulmonary vascular resistance and marked increase in pulmonary blood flow at birth. The results from our in vitro experiments indicate that the vasodilator effect of $\mathrm{BK}$ in the perinatal pulmonary circulation is mediated by EDRF. Prostacyclin production with the onset of breathing at birth appears to play a minor role in the pulmonary hemodynamic adjustments at birth based on experiments with acute cyclooxygenase blockade in chronically instrumented, spontaneously breathing lambs (16). Inasmuch as high circulating levels of vasoconstrictors such as catecholamines and angiotension II are elevated and contribute to the increase in systemic vascular resistance at birth $(17,18)$, EDRF could play a counterbalancing role in the pulmonary circulation. Attention is now turning to the relief of hypoxic pulmonary vasoconstriction as the principal process involved in the decrease in pulmonary vascular resistance at birth (19). The role of endothelial cell and EDRF production during hypoxia appears to be a new avenue for research (20).

Using the newborn guinea pig, our study demonstrates for the first time that EDRF is produced in pulmonary and systemic arteries immediately after birth. Further studies are needed in perinatal animals to determine whether there are differences in EDRF production or action between species and with development. Our study, taken together with recent work showing that ACh causes vasodilatation in pulmonary hypertensive calves (21), suggests that regional stimulation of lung EDRF production or administration of exogenous EDRF could play a therapeutic role in pulmonary hypertensive diseases of the newborn.

Acknowledgments. The authors thank Drs. P. Lipsitz, R. Bienkowski, and E. Scarpelli for their support and critical review of the manuscript. The multiple bioassay stand and controls were custom made by Fred Singer of Koehler Instrument Company, Bohemia, NY. The support of Diane Davidson is gratefully acknowledged.

\section{REFERENCES}

1. Furchgott RF, Zawadzki JV 1980 The obligatory role of endothelial cells in the relaxation of arterial smooth muscle by acetylcholine. Nature 288:373376

2. Furchgott RF 1988 Endothelium-dependent relaxation in systemic arteries. In: Vanhoutte PM (ed) Relaxing and Contracting Factors, Biological and Clinical Research. The Humana Press, Inc., Clifton, NJ, pp 1-21

3. Ignarro LJ, Byrns RE, Buga GM, Wood KS 1987 Mechanisms of endotheliumdependent vascular smooth muscle relaxation elicited by bradykinin and VIP. Am J Physiol 253:H1074-H1082

4. Martin W, Villani GM, Jothianadan D, Furchgott RF 1985 Selective blockade of endothelium-dependent and glyceryl trinitrate-induced relaxation by hemoglobin and by methylene blue in the rabbit aorta. J Pharmacol Exp Ther 228:682-690

5. Lewis AB, Heymann MA, Rudolph AM 1976 Gestational changes in pulmonary vascular responses in fetal lambs in utero. Circ Res 39:536-541

6. Melmon KL, Cline MJ, Hughes T, Nies AS 1968 Kinins: possible mediators of neonatal circulatory changes in man. J Clin Invest 47:1295-1302

7. Gruetter CA, Gruetter DY, Lyon JE, Kadowitz PJ, Ignarro LJ 1981 Relationship between cyclic guanosine $3^{\prime} \cdot 5^{\prime}$ ' monophosphate formation and relaxation of coronary arterial smooth muscle by glyceryl trinitrate, nitroprusside, nitrite and nitric oxide: effects of methylene blue and methemoglobin. J Pharmacol Exp Ther 219:181-186

8. Winer RJ 1962 Statistical Principles in Experimental Design. McGraw-Hill, New York, pp 591-595

9. deVoorde JV, Vanderstichele H, Leuson I 1987 Release of endothelium-derived relaxing factor from human umbilical vessels. Circ Res 60:517-522

10. Milner PG, Izzo NJ, Saye J, Loeb AL, Johns RA, Peach MJ 1988 Endotheliumdependent relaxation is independent of arachidonic acid release. J Clin Invest 81:1795-1803

11. Palmer RMJ, Ferrige AG, Moncada S 1987 Nitric oxide release accounts for the biological activity of endothelium-derived relaxing factor. Nature 327:524-526

12. Crutchley DJ, Ryan JW, Fisher GH 1983 Bradykinin-induced release of prostacyclin and thromboxanes from bovine pulmonary artery endothelial cells. Biochem Biophys Acta 751:99-107

13. Johns RA, Peach MJ 1988 Metabolism of arachidonic acid and release of endothelium-derived relaxing factors. In: Vanhoutte PM (ed) Relaxing and Contracting Factors, Biological and Clinical Research. The Humana Press, Inc., Clifton, NJ, pp 1-21

14. Shimokawa H, Flavahan NA, Lorenz RR, Vanhoutte PM 1988 Prostacyclin releases endothelium-derived relaxing factor and potentiates its action in coronary arteries of the pig. Br J Pharmacol 95:1197-1203

15. Leffler CW, Hessler JR, Green RS 1984 The onset of breathing stimulates pulmonary vascular prostacyclin synthesis. Pediatr Res 18:938-942

16. Davidson D 1988 Pulmonary hemodynamics at birth: effect of acute cyclooxygenase inhibition in lambs. J Appl Physiol 64:1676-1682

17. Padbury J, Agata Y, Ludlow J, Ikegami M, Baylen B, Humme J 1987 Effect of fetal adrenalectomy on catecholamine release and physiologic adaptation at birth in sheep. J Clin Invest 80:1096-1103

18. Davidson $D 1987$ Circulating vasoactive substances and hemodynamic adjustments at birth in lambs. J Appl Physiol 63:676-684

19. Morin FC, Egan EA, Ferguson W, Londgren CEG 1988 Development of pulmonary vascular response to oxygen. Am J Physiol 254:H542-H546

20. Holden WE, McCall E 1984 Hypoxia-induced contractions of porcine pulmonary artery strips depend on intact endothelium. Exp Lung Res 7:101112

21. Orton CE, Reeves JT, Stenmark KR 1988 Pulmonary vasodilation with structurally altered pulmonary vessels and pulmonary hypertension. $\mathbf{J}$ Appl Physiol 65:2459-2467 